\title{
Development Strategies of Leisure Sports Industry and It's Significance on the Process of Turning Chengdu into an Oriental Capital of Leisure
}

\author{
Wei Ren \\ Chengdu Medical College, Chengdu, Sichuan Province, China
}

Keywords: Chengdu; Leisure Sports Industry; Oriental Capital of Leisure.

\begin{abstract}
This article analyzes the main content of leisure sports industry and it's significance on the process of turning Chengdu into an oriental capital of leisure. Leisure sports industry could be a new economic growth point in Chengdu. Through the gradually constructing of this sunrise industry with low energy consumption and high added value, the economic structure of Chengdu can be adjusted. Leisure sports industry can also promote the improvement of people's living standards, and create more value for the economic development of Chengdu. It also helps the city to build a new social image. From the perspective of human care, the space of leisure sports could be expanded, the development of industrial clusters could be realized. The integration between leisure sports industry and other industries could also be promoted..
\end{abstract}

\section{Introduction}

The development of leisure sports industry can promote the uplifting of urbanization level and the development of regional economy. The construction of leisure sports industry in Chengdu meets citizens' demands and provides them with cheerful psychological experience. Thus, people can work, study and live in a free and comfortable environment. Leisure sports industry can release residents' mental pressure to the maximum, and it is an important factor in evaluating the development level of regional sports business. Leisure sports industry closely relate to regional sports business, and can link residents' leisure quality to sports activities. It also helps people to form a positive attitude towards life, and plays an essential role in the process of construction Chengdu an oriental capital of leisure.

\section{Concept of Leisure Sports Industry}

Leisure sports industry refers to industry clusters provided by various social sectors and closely related to citizens' physical activities. It includes sports products and services, as well as the business activities which are related to these products and services. With the development of social economy, people's material demands have been met. Since the basic survival requirements have been satisfied, people today pay more attention to art, culture and other social activities. It is a important feature of social development that people are now using their leisure time to take part in sports activities. The development of leisure sports industry can promote the improvement of economic conditions, effectively stimulate the demand of domestic consumption, actively adjust the industrial structure and increase employment opportunities. It is an important driving force for social development. The aim of leisure sports industry is to reasonably and effectively allocate social resources according to the basic law of market economy, to meet people's basic needs of physical activities, and to help people take part in sports activities in a cheerful environment. Leisure sports industry can promote the all-round development of people and help citizens to build a harmonious socialist society. It is a national strategy in achieving the goal of comprehensive sports development.

\section{Necessity of Building Chengdu as Oriental Capital of Leisure}

Firstly, leisure sports industry has gradually become a new economic growth point in Chengdu. The traditional economic growth points are now not able to meet the needs of Chengdu citizens. A comprehensive study on new development patterns of Chengdu needs to be done. Leisure sports 
industry should develop on the basis of traditional economic condition. In this way, adjustment of economic structure could be achieved, and the brand awareness together with innovation ability in Chengdu leisure sports industry can be cultivated. The geographic and economic advantages of Chengdu should be fully took, and the leisure sports products with cultural characteristics should be created and sold.

Secondly, leisure sports industry is a sunrise industry with low energy consumption and high added value. With the rapid economic development in Chengdu, people begin to pay more attention to their physical conditions. Sports consumption has already occupied a large proportion in citizens' total income. People's consumption concepts and patterns are changed. Leisure sports industry can provide Chengdu residents with more advanced sports activities. At the same time, sports activities which are taken place in a happy and free atmosphere can promote the comprehensive development of people. Leisure sports industry with low energy consumption and high added value also plays an important role in optimizing people's consumption structure. Leisure sports industry in Chengdu is relatively developed in China, and has took essential effects in enhancing the material foundation of Chengdu.

Thirdly, the development of leisure sports industry can promote the adjustment and development of industrial structure. In Chengdu, industrial structure adjustment is an important factor in economic development. In the sports industry, income increase is mainly achieved through peripheral products like sports clothes. Sports competition serves as the main body of sports industry income, while other aspects of sports competition do not reach the effect of promoting the industry overall. The unreasonable industrial structure greatly limits the economic development of Chengdu. The connections between industries are relatively close, and a variety of industries in Chengdu should be linked to promote the constant development of economy. Consumption structure which targets at leisure city should also be adjusted actively. The general development strategy should be made according to market changes. Universal fitness activities need to be advocated actively, and national sports industry base should be built. The cooperation between leisure sports industry and other industries should also be promoted.

\section{Significance of Leisure Sports Industry on the Process of Turning Chengdu into an Oriental Capital of Leisure}

Firstly, leisure sports industry can improve the living standards of Chengdu residents. Leisure sports industry can highlight the characteristics of central cities, and lay a foundation for the future development of leisure sports industry. Changes on people's lifestyle help them to build healthy bodies, while the rhythm of people's life can lead them to ask construction questions. Leisure sports is an important form of relaxation. It can offer good atmosphere for people's healthy activities. It reflects the needs of people's all-round development, promotes the improvement of people's life quality constantly, and actively helps them to build new habits. These positive effects enable people to better adapt to the rapid social changes. The building of positive and healthy lifestyle needs people's subjective initiatives and their attention to the effects of lifestyle on their life quality. Leisure sports has become the mainstream of social quality improvement, and its effects on enriching people's life and improving social atmosphere is crucial. Through the development of leisure sports, Chengdu residents can improve their living standard and turn Chengdu into an oriental capital of leisure actively.

Secondly, leisure sports industry can create wealth and value for Chengdu. The improvement of people's economic level requires continuously increasing of sports activities. Thus, a huge sports consumption group in Chengdu is founded. This group create opportunities for economy growth. Sports consumption has already occupied a large proportion of people's total income; their consumption concepts and patterns are also changing. Developed sports industry can show the prospect of leisure sports market. It can actively drive the adjustment of industry, promote the economic development of Chengdu, and stimulate enterprises to spend more money on urban development. The combination of tourism and leisure sports industry is an innovative application of new model on economic development, and it can further exploit the economic potential of Chengdu. 
Under the administration of economic authorities, the new measures of economic development should be made. New policy needs to pay attention to the application of leisure elements, adjust the traditional economic model, control the proportion of leisure sports on the basis of changes on market demands, optimize the industrial structure and promote the economic transformation. Development on city economic integration diversifies leisure sports industry, while healthy and harmonious sports activities can meet the more and more needs of Chengdu people.

Thirdly, leisure sports industry can improve the image of Chengdu. In Chengdu, the industry of leisure sports develops on the basis of its own tradition. It is an important form of Chengdu residents' leisure activities. It also helps Chengdu people to achieve the transformation from sightseeing to leisure life. It changes people's life style. Chengdu's leisure culture characteristics make residents here live more flexibly and relaxed. The most obvious feature of leisure sports in Chengdu is the integration of the humanities, entertainment and life, and this integration is not possessed by other cities. Chengdu has set up a new city image through the development of leisure sports industry. Through the leisure sports industry, more people realize the development of Chengdu, and then become fond of Chengdu. Chengdu residents can put more effort into the building of Chengdu city, and face the development of Chengdu with a positive and enthusiastic attitude.

\section{Development Strategies of Leisure Sports in Chengdu}

Firstly, expand the space of leisure sports from the perspective of human care. Playing leisure sports can develop people's love towards nature, and it is an important foundation of building harmonious society. Changes in human society development will directly influence the implement of activities. Residents in Chengdu construct leisure sports industry through actively participating in leisure sports activities, especially outdoor sports activities. These activities enable people to fully realize the charm of nature and to comprehend the true meaning of life. Then, they will put more enthusiasm into the charming scenery of nature. The development of leisure sports activities in natural environment will improve the quality of people's physical exercises, strengthen their awareness of environment protection, and push them to turn their ideas into action. The harmonious relationship between human and nature provides an important foundation for citizens' good living environment, and helps people to improve their physical and mental status. It also helps people to completely relax themselves from fierce competition, and plays an important role in the development people's life in the future. Moreover, it can enhance the harmonious relations between citizens, and reduce the number of utilitarian. Leisure sport activity is an important carrier of humans' interaction. This psychological experience asks people to organize groups freely and open their mind. It eliminates barriers between group members, and helps them to find themselves. Through leisure sports, people can experience the joy of success, actively adjust their psychological activities, reduce stress, and deal with the harmfulness of sub-health better. From the perspective of human care, the expansion of leisure sport space is an important study of innovations in leisure sports development. Combining leisure sports with humanistic values can promote the development of leisure sports, enable leisure sports industry to adapt with social changes better and to meet people's requirements continuously.

Secondly, industrial clusters should be achieved. Industry clusters can make different industries cooperate with each other in specific areas. Advantages on resources and geography can also be used effectively to promote the mutual help between industries which can support each other. Promoting of centralized industrial supply and characteristic service can be achieved. Financial function should be used, too. Building of industry clusters needs to be related to their industrial characteristics. Leisure sports industry can play an important role in different industry clusters, and through the leisure sports industry, complex market changes can be processed simply in the economic organization space. Through the adjustment of market service and customer relationship, industry clusters can help leisure sports industry to achieve the goal of industry specialization training and the development and application of information. Professional institutions with professional standards can also be built. Development of sports industry clusters helps leisure industry to develop beyond the scope of industry, and forms the development trend of combining industries in specific regions to realize the 
symbiotic system among numerous agencies. Regional characteristics are main features of these industry clusters, and the formation of economy clusters will raise the economic level in this region. It is also an important feature of economic development. As for the industrial structure, clusters can help to realize the deep processing of leisure sport products, and strengthen the industrial chain. It is also an important way to optimize and upgrade the leisure sports industry. In the development process of leisure sports clusters, different companies will form an integrated management pattern. Adjusting of industrial structure and construction of industrial organization are keys to the formation of industrial clusters.

Thirdly, promoting the cooperation between leisure sports industry and other industries. The changing market needs the cooperation between leisure sports industry and other industries. Accelerating social pace deprive people's leisure time, and prevent them from effectively releasing their depression. But when travailing, people can pursue their physical and mental changes, and realize their targets of self-value. Leisure sports can provide people with pleasant experience and colorful social platform. Leisure sports industry can make people actively involved in the leisure sports tourism, which can improve their taste and make them feel more excited. Mass consumption is a brand new experience, while spiritual enjoyment will get more attention. The cooperation between sports and tourism industry is the basis of industrial connecting in this changing market. Promoting the integration of leisure sports industry and other industries can achieve the goal of resource sharing, since all of these industries have their advantages. Through the effective integration, these advantages, both tangible and intangible, can be shared. They are all methods to use natural resources. In the public industry platform, several goals on fundamental industrial resources need to achieved in the process of their building and operating. The most important one is brand construction of regional resources, including the regional landscape. Intangible resources needs to be treated specifically. In the sports industry, brand activities with professional characteristic should be carried out according to different standards of tourism. In the process of regional resources improvement, the value of intangible and tangible resources should be promoted in the base, and trying to form brand attraction. Especially in sports industry, related sports bases are needs to be built. Sports products should be appreciated as important experience in traveling. In the tourism industry, sports venues should be built with tangible resources, and fitness activities with specific plans should be formulated. These improvements enable tourists to play sports when they traveling. Enhancement of the influence of leisure sports industry will help Chengdu to build the oriental capital of leisure better.

The development of leisure sports industry is closely linked to economic situation. In order to turning Chengdu into the oriental capital of leisure , the construction of leisure sports industry should also be emphasized when we promote the development of economy. The constant promotion of leisure sports industry can make important contributions to the sustainable economic development. In the new environment condition, optimizing the structure of Chengdu leisure sports industry and reviewing the leisure sports industry in detail, can gradually promote the development of core cities, and turn Chengdu into an oriental capital of leisure with Chinese characteristics.

\section{Acknowledgement}

Foundation for General Projects of the Key Research Center on Humanities and Social Sciences (Le isure Sports Industry) of Education Department of Sichuan Province in 2014 (Project No.:

XXTYCY2014B14).

\section{References}

[1] DU Shuang-shuang. The Development of Leisure Sports and Leisure Traits in the Construction Background of Chengdu "World-class Modern Garden City" [D].Chengdu sports Institute, 2012, 6, 11.

[2] MAO Ting-ting. Study on the development of urban leisure sports and local government decision [D].Jimei University, 2014, 4, 15. 
[3] GUO Xiu-jin. Research on the Interaction Relations between Leisure Sports and Leisure City Development_— Taking the Example of Hangzhou, Shanghai and Chengdu [J]. Journal of Nanjing Institute of Physical Education (Social Sciences), 2011, 10, 15.

[4] ZHAO Dao-jing \& PAN Lei. Research on the cluster formation of leisure sports industry in Wuhan [J]. JOURNAL OF LESHAN TEACHERS COLLEGE, 2013, 12, 15. 